\title{
Autoevaluación de docentes en competencias tecno-pedagógicas para la elaboración de materiales didácticos virtuales
}

\section{Professors' self-assessment techno-pedagogical skills in the development of educational resources for a virtual modality}

\author{
Laura Cristina Piñón Howlet \\ Universidad Autónoma de Chihuahua (México) \\ Ipinon@uach.mx \\ http://orcid.org/0000-0002-1176-2567 \\ Alma Lilia Sapién Aguilar \\ Universidad Autónoma de Chihuahua (México) \\ Isapien@uach.mx \\ http://orcid.org/0000-0001-7222-2612 \\ María del Carmen Gutiérrez Diez \\ Universidad Autónoma de Chihuahua (México) \\ cgutierr@uach.mx \\ http://orcid.org/0000-0001-9159-3283
}

Fechas · Dates

Recibido: 2019-08-20

Aceptado: 2019-10-12

Publicado: 2019-12-31
Cómo citar este trabajo $\cdot$ How to Cite this Paper

Piñón, L. C., Sapién, A. L., \& Gutiérrez, M. C. (2019). Autoevaluación de docentes en competencias tecno-pedagógicas para la elaboración de materiales didácticos virtuales. Publicaciones, 49(5), 161-177. doi:10.30827/publicaciones.v49i5.8318 


\title{
Resumen
}

Una adecuada preparación de materiales didácticos para la modalidad virtual involucra un proceso de diseño donde los docentes se apoyan en herramientas de tecnologías de información y comunicaciones. La enseñanza actual está demandando docentes debidamente entrenados en la creación, diseño e implementación de materiales didácticos.

El objetivo de la presente investigación fue realizar un diagnóstico de las competencias tecno-pedagógicas de los docentes para la elaboración de materiales didácticos para la modalidad virtual. El estudio se realizó en el 2016 en la Facultad de Contaduría y Administración de la Universidad Autónoma de Chihuahua, México. La investigación fue no experimental, descriptiva y la unidad de análisis fueron 56 maestros que impartieron clases en la modalidad virtual y que tenían más de un año de antigüedad en esta modalidad.

Se utilizó un cuestionario de 38 preguntas cerradas; se solicitaba un grado de acuerdo o desacuerdo (escala Likert). Para la variable de materiales didácticos se consideraron cuatro dimensiones: competencia en diseño instruccional, características, competencia tecnológica, servicios y soportes. Los resultados mostraron que los docentes carecen de las competencias demandadas para la elaboración de materiales didácticos para la modalidad virtual. Requieren de competencia para la elaboración de materiales con un diseño didáctico acorde a las características de los estudiantes, que responda al logro de objetivos formativos establecidos, así como también necesitan del uso estrategias didácticas que integren las TIC en el proceso educativo.

Palabras clave: Materiales didácticos; educación virtual; competencias TIC; competencia pedagógica; autoevaluación docentes

\begin{abstract}
The proper preparation of didactic materials for the virtual modality involves a process of design with information and communication technologies. The current teaching is suing properly trained teachers in the creation, design and implementation of teaching materials. The objective of this research was to make a diagnosis of professor's techno-pedagogical skills to develop teaching materials for the virtual mode competencies. The study conducted in 2016 at the Faculty of Accounting and Administration of the Autonomous University of Chihuahua, Mexico. The study was not experimental, descriptive and analytical unit were 56 professors who teach in the virtual mode and had more than one year old in this mode. A questionnaire of 38 closed questions was used; in which, in response a degree of agreement or disagreement (Likert scale) is requested. For the variable of educational materials were considered four dimensions; competition in instructional design, features, technological expertise, services and supports. The results showed that professors do not have the competences required for the development of teaching materials for the virtual mode. Require competence for the development of educational materials with a design according to the characteristics of the students, who respond to the educational achieving established objectives, and need to use teaching strategies that integrate ICT in the educational process.
\end{abstract}

Key words: Didactic materials; virtual education; ICT skills; pedagogical skills; Professors' self-assessment 


\section{Introducción}

La educación superior, a nivel mundial, ha tenido que innovarse para dar respuesta a los cambios económicos, culturales y sociales que ha traído la globalización. Estas innovaciones conllevan a la necesidad del mejora de la calidad educativa. Todos los procesos, en la actualidad, son más complejos y dinámicos, por lo que los métodos que tradicionalmente se utilizaban, no son aceptables para una apropiada planificación y gestión. Es claro, entonces, que también la educación superior necesita adaptarse a este nuevo y dinámico entorno que la rodea, en el que el futuro inmediato está caracterizado por nuevos desafíos (Rodríguez et al., 2014).

Hoy en día, las tecnologías de información y comunicación (TIC) han proporcionado la posibilidad de experimentar situaciones de aprendizaje en cualquier momento, sin que se dependa de horarios, desde cualquier lugar, sin necesidad de la presencia física, y utilizando cualquier dispositivo como medio de interacción. Gracias a las TIC se ha ampliado el abanico de posibilidades del docente a la hora de plantear metodologías innovadoras (Aznar-Díaz et al., 2016). En consecuencia, surgen dos preguntas clave en el proceso de reinventar el papel de los docentes. La primera es ¿Tienen los docentes las competencias indispensables para la elaboración de materiales didácticos pertinentes para la modalidad virtual? La segunda sería ¿Los docentes adscritos a la modalidad virtual cuentan con los recursos disponibles y el apoyo para la elaboración de los mismos?

Con base a lo anterior, el objetivo general de esta investigación fue realizar un diagnóstico de las competencias tecno-pedagógicas en la elaboración de materiales didácticos para la modalidad virtual, a partir de la autoevaluación de docentes. Los objetivos específicos que se desprenden de este objetivo general fueron: 1) caracterizar la competencia en tecnologías de información y comunicación en los docentes; 2) determinar la competencia en diseño instruccional para la elaboración de materiales didácticos; 3 ) identificar si los docentes disponen de recursos y apoyo para la elaboración de los materiales didácticos; y 4) realizar un análisis de brechas para comparar las diferencias entre importancia (dominio deseado) y nivel de desarrollo o dominio (dominio existente) de las competencias tecno-pedagógicas de los docentes de la Universidad Autónoma de Chihuahua. Los principales beneficiarios o usuarios potenciales de estos conocimientos serán, en primer lugar, los investigadores y docentes que intervinieron en el trabajo; $y$, en segundo término, las instituciones de educación superior para tomar conciencia de la realidad y de la importancia de la preparación y apoyo a los docentes de educación virtual en la elaboración y diseño de materiales didácticos.

\section{Marco Teórico}

\section{Tecnologías de la información y la comunicación}

Carmona y Rodríguez (2017) señalan que las Tecnologías de la Información y la Comunicación (TIC) involucran a un conjunto de tecnologías entre las cuales se incluyen, la informática, telecomunicaciones y redes de dispositivos móviles. Las TIC se han convertido en recursos importantes para el desarrollo de todas las esferas de la vida. Por lo tanto, es difícil desestimar el papel medular que en la actualidad han tenido las TIC en la educación (Pellón et al., 2017). Las TIC aplicadas a la educación, surgen como sistemas de apoyo, tanto a la formación presencial, como al aprendizaje 
en línea, creando nuevos entornos, los cuales, oscilan desde la virtualidad como apoyo a la educación presencial, hasta la virtualidad total. Coll y Monereo (2008) comentan que las TIC no innovan o cambian nada por el sólo introducirse en las instituciones educativas, ya que el principal reto consiste en la generación y puesta en marcha de planteamientos psicoeducativos y didácticos desde los que se plantea su utilización con fines educativos.

Torres y Gutiérrez (2017) señalan que las investigaciones referentes al uso de las TIC muestran acciones y métodos pedagógicos que continuamente combinan experiencias y modelos didácticos con el uso de éstas. Esta combinación está enfocada en obtener la eficiencia y eficacia educativa para lograr el aprendizaje y una mediación innovadora en los procesos de enseñanza.

\section{Educación Virtual}

Facundo (2010) especificó que la educación virtual consiste en utilizar los medios tecnológicos para la distribución de contenidos, así como para la realización de las mediaciones pedagógicas. Con los avances tecnológicos que se presentan de una manera dinámica, también la educación virtual tendrá que evolucionar. De acuerdo con las tecnologías y diseños que se utilicen en la educación, se podrán incorporar lenguajes multimedia como imágenes, audio digital, videos digitales, nuevos dispositivos para actividades en el aula virtual como exámenes cortos, encuestas, boletines y calendarios, así como diversas formas de comunicación como chat, foros y contenidos que incluyan objetos de aprendizaje.

La inclusión de las Tecnologías de Información y Comunicación (TIC) en la educación, ha generado nuevas didácticas así como ha potenciado ideales pedagógicos formulados por docentes, psicólogos y epistemólogos tales como: 1) ofrecer al estudiante diversos ambientes de aprendizaje ricos en materiales y experiencias que capten su interés; 2) otorgarle una mayor libertad para explorar, observar, analizar y construir conocimiento; 3) estimular su imaginación, creatividad y pensamiento crítico; 4) ofrecerle múltiples fuentes de información más sustantivas y actualizadas y; 5) permitirle realizar experiencias de aprendizaje multisensorial (Campo et al., 2013). Los investigadores Lloréns et al. (2013) comentaron que, en la educación a distancia, los recursos tecnológicos y didácticos juegan un papel decisivo para el óptimo desarrollo del proceso de enseñanza-aprendizaje. Cualquiera que sea la tecnología que los soporte, los materiales para la enseñanza a distancia deberán facilitar el aprendizaje autónomo, por un lado, y ser autosuficientes, por el otro (Tynybekova et al., 2013). En esta modalidad, en particular, es imprescindible que el material incluya las orientaciones, los elementos motivadores, el desarrollo de los contenidos clarificador-estimulante y los refuerzos e indicaciones necesarias; de tal manera que, el alumno, logre alcanzar los objetivos de aprendizaje previstos mediante el estudio independiente (o con apoyo tutorial).

Por esta razón, comprender el significado de recursos didácticos es fundamental para entender el cómo transmitir de la mejor manera el conocimiento. Corrales y Sierras (2012) definieron como recursos didácticos, todos aquellos instrumentos que, por una parte, ayudan a los formadores en su tarea de enseñar, y por otra, facilitan a los alumnos el logro de los objetivos de aprendizaje. En otro estudio, Lokar (2011) señaló que los materiales didácticos deberían ser diseñados de manera flexible y apoyados por el uso apropiado de las herramientas de TIC. Por esta razón, una adecuada preparación de materiales didácticos para su implementación en la modalidad virtual, deberá in- 
cluir todo el proceso de diseño, uso y modificación. No obstante, los docentes deberán tener la posibilidad de adaptar los materiales, respetando los conocimientos, habilidades y necesidades de sus alumnos. Combinar las tecnologías con los conocimientos pedagógicos del docente.

\section{Competencias tecno-pedagógicas}

Las competencias tecno-pedagógicas son el integrar las tecnologías en las aulas combinando los conocimientos pedagógicos del docente. Según Mishra y Koehler (2006) el conocimiento pedagógico tecnológico es el conocimiento de la existencia, componentes y capacidades de las distintas tecnologías que se utilizan en la enseñanza y aprendizaje de valores. Mishra y Koehler (2006) argumentan que no solo la búsqueda de la introducción de la tecnología en el proceso educativo no es suficiente, si no que los maestros necesitan saber incorporar adecuadamente la tecnología en su enseñanza. Antonenko et al. (2004) comentan que las bases tecnológicas afectan a cómo los medios pueden apoyar, limitan o mejoran la pedagogía del entorno de aprendizaje.

En la actualidad, el papel del docente se ha redefinido. Su principal tarea es guiar al estudiante a través de elementos de información como recursos didácticos hacia el conocimiento. Esto implica, el requisito de concretar el contenido educativo y adaptarlo a los intereses y habilidades del alumno en particular. Resulta claro que los alumnos son diferentes, pero la práctica educativa existente y los materiales que la apoyan están cambiando muy lentamente. En otras palabras, las instituciones educativas siguen utilizando materiales didácticos que fueron desarrollados para enseñar a los estudiantes de hace décadas. Sin embargo, los estudiantes de este nuevo milenio son, en realidad, muy diferentes de sus antecesores. Ante este contexto educativo que, obviamente, presenta nuevas necesidades de formación, es preciso contar con un número suficiente de directivos, planificadores, autores, técnicos y docentes. Pero, además, es necesario que todos estos profesionales, estén preparados y comprometidos con el importante papel de diseñar y elaborar materiales didácticos, con asesoramiento pedagógico.

\section{Metodología}

Se condujo una investigación empírica con un enfoque cuantitativo, de tipo aplicada, no experimental con apoyo bibliográfico, que se basó en una encuesta donde el objeto de estudio fueron los materiales didácticos. La población bajo estudio fueron 69 docentes que impartieron clases en la modalidad virtual y los cuales tienen más de un año de antigüedad en esta modalidad. Todos los participantes se encuentran adscritos a la Facultad de Contaduría y Administración (FCA) de la Universidad Autónoma de Chihuahua (UACH). La información básica fue proporcionada por la coordinación académica de la modalidad virtual de la FCA, de donde se obtuvo la muestra. Se utilizó un muestreo aleatorio simple con un error del 5\%. La aplicación de dicha ecuación dio como resultado la obtención de una muestra total de 56 docentes. El instrumento de medición utilizado fue un cuestionario, el cual fue diseñado colegiadamente entre expertos y especialmente diseñado para evaluar la variable de materiales didácticos. El cuestionario fue integrado por un total de 38 preguntas cerradas con escala tipo Likert con 2 subescalas de valoración: una referida a la importancia de cada atributo y la correspondiente al nivel de dominio que los encuestados consideran poseer de cada atributo. 
En la Tabla 1 se muestra, a nivel de detalle, cómo se realizó la sistematización de la variable materiales didácticos. Como se puede observar se consideraron las siguientes cuatro dimensiones; la competencia en diseño instruccional, las características del material didáctico que elabora, la competencia tecnológica y, finalmente, los servicios y soportes. Además, en la Tabla 1 se especifican los indicadores para cada dimensión y los atributos para cada indicador. La confiabilidad del instrumento fue calculada utilizando el coeficiente de consistencia interna de Cronbach, que reportó resultados aceptables $(a \geq 0.80)$. Para el análisis de los datos, se realizó un análisis de frecuencias y de porcentajes utilizando el paquete estadístico SPSS para cada una de las dimensiones e indicadores.

\section{Tabla 1}

Sistematización de la variable de estudio

\begin{tabular}{|c|c|c|c|c|}
\hline Variable & Dimensiones & Indicadores & atributos & Total \\
\hline \multirow[t]{4}{*}{$\begin{array}{l}\text { Materiales } \\
\text { didácticos }\end{array}$} & $\begin{array}{l}\text { Competencia } \\
\text { en diseño } \\
\text { instruccional }\end{array}$ & $\begin{array}{l}\text {-Fundamentos básicos } \\
\text {-Análisis y planeación } \\
\text {-Diseño y desarrollo } \\
\text {-Implementación y } \\
\text { administración }\end{array}$ & $\begin{array}{l}1-10-19 \\
3-4-8-11-15 \\
2-5-9-12- \\
16-17 \\
6-7-13-14- \\
18-20\end{array}$ & 20 \\
\hline & Características & Estructura & Del 21 al 28 & 8 \\
\hline & $\begin{array}{l}\text { Competencia } \\
\text { Tecnológica }\end{array}$ & $\begin{array}{l}\text {-Uso y selección de } \\
\text { herramientas pertinentes } \\
\text {-Uso de TIC en el proceso } \\
\text { enseñanza aprendizaje } \\
\text {-Uso de TIC para expresase } \\
\text { y relacionarse }\end{array}$ & $\begin{array}{l}29-31-32 \\
30-33-34-35 \\
36\end{array}$ & 8 \\
\hline & Servicios y soporte & $\begin{array}{l}\text { Evalúa la disponibilidad } \\
\text { de servicios de atención al } \\
\text { docente para desarrollar } \\
\text { sus materiales didácticos }\end{array}$ & $37-38$ & 2 \\
\hline
\end{tabular}

Además, se realizó un estudio integracional a través del análisis de brechas lo que permitió comparar las diferencias entre importancia (dominio deseado) y nivel de desarrollo o dominio (dominio existente) de dos de las dimensiones las cuales se agruparon por competencia en diseño instruccional (4 indicadores con 20 atributos) y competencia tecnológica (3 indicadores con 8 atributos). Este diagnóstico permitió identificar la situación actual de los profesores en la Universidad Autónoma de Chihuahua.

\section{Análisis y resultados}

Se presentarán los resultados diferenciándolos en función de los objetivos que se han planteado, analizando, en primer lugar, las competencias a través de un análisis de frecuencias y de porcentajes y, en segundo lugar, un análisis de brechas a partir del análisis de las medias obtenidas de cada competencia por su importancia y su nivel. 


\section{Competencia docente en tecnologías de información y comunicaciones}

(TIC)

En la figura 5, se muestra que el $53 \%$ de los docentes consideraron que definitivamente sí y probablemente sí poseen la competencia tecnológica para la elaboración de los materiales didácticos para la modalidad virtual. Sin embargo, la sumatoria del resto de las cifras alcanzó $47 \%$, los cuales consideran que probablemente no y definitivamente no utilizan variedad de textos e interfaces para transmitir información y expresar ideas propias combinando texto, audio, imágenes estáticas o dinámicas, vídeos y gestos en sus materiales didácticos.

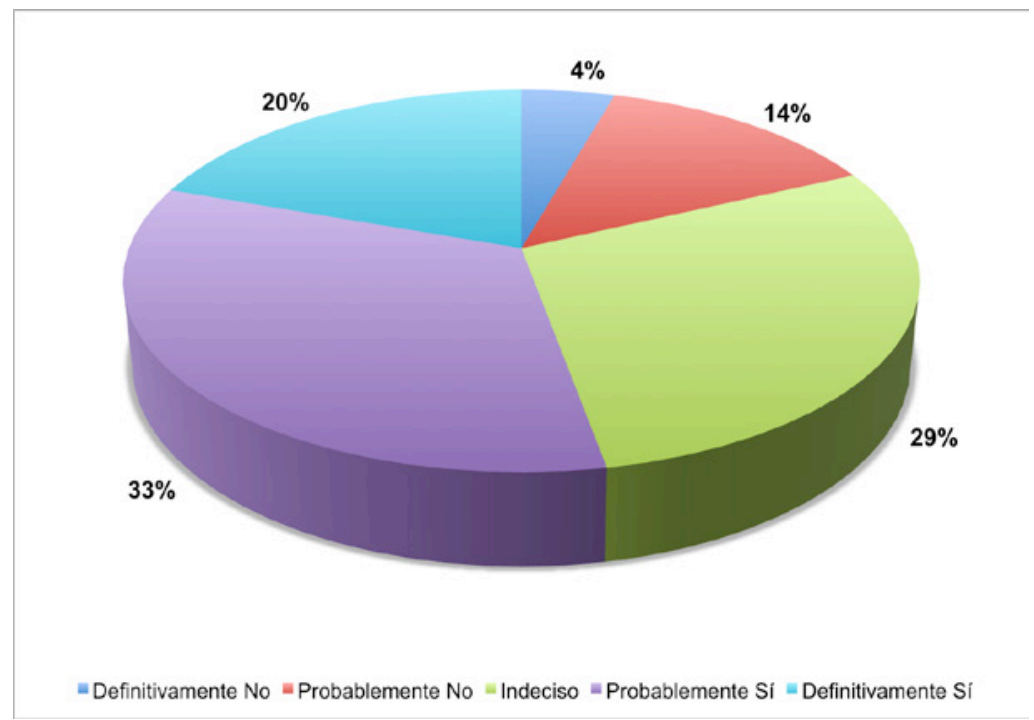

Figura 1. Competencia docente en tecnologías de información y comunicaciones

Al respecto de la competencia en TIC, se analizarán los indicadores que resultaron. Para identificar los aspectos débiles de ésta competencia se analizarán en las siguientes tablas de frecuencias.

Tabla 2

Conocimiento de las características de los materiales en la enseñanza mediada por la tecnología, los elementos que la componen, los formatos y tipologías

\begin{tabular}{lllll}
\hline & Frecuencia & Porcentaje & $\begin{array}{l}\text { Porcentaje } \\
\text { válido }\end{array}$ & $\begin{array}{l}\text { Porcentaje } \\
\text { acumulado }\end{array}$ \\
\hline Definitivamente No & 2 & 3.6 & 3.6 & 3.6 \\
Probablemente No & 8 & 14.3 & 14.3 & 17.9 \\
Indeciso & 27 & 48.2 & 48.2 & 66.1 \\
Probablemente Sí & 13 & 23.2 & 23.2 & 89.3 \\
Definitivamente Sí & 6 & 10.7 & 10.7 & 100.0 \\
Total & 56 & 100.0 & 100.0 & \\
\hline
\end{tabular}


La tabla 2, señala que el $66.1 \%$ de los docentes consideran que están indecisos, probablemente no y definitivamente no tienen el conocimiento de las características de los materiales en la enseñanza mediada por la tecnología, los elementos que la componen, los formatos y tipologías. La importancia de la tecnología para la enseñanza es indiscutible gracias al desarrollo y los avances que se han tenido; el éxito de la docencia, así como el placer de los alumnos el aprovechamiento y aprendizaje, dependen de ella en gran medida. Por tanto, es indispensable que el maestro de hoy conozca los materiales de enseñanza para utilizarlos adecuadamente, imprimiéndoles vida y significación, de tal manera que proporcione al estudiante una variedad de experiencias, y le facilite la aplicación de su aprendizaje en la vida real.

\section{Tabla 3}

Capacidad en el uso y manejo del software específico para el diseño de materiales en diversos formatos (textual, hipertextual, multimedia, entre otros)

\begin{tabular}{lllll}
\hline & Frecuencia & Porcentaje & $\begin{array}{l}\text { Porcentaje } \\
\text { válido }\end{array}$ & $\begin{array}{l}\text { Porcentaje } \\
\text { acumulado }\end{array}$ \\
\hline Probablemente No & 15 & 26.8 & 26.8 & 26.8 \\
Indeciso & 13 & 23.2 & 23.2 & 50.0 \\
Probablemente Sí & 13 & 23.2 & 23.2 & 73.2 \\
Definitivamente Sí & 15 & 26.8 & 26.8 & 100.0 \\
Total & 56 & 100.0 & 100.0 & \\
\hline
\end{tabular}

El 50\% de los docentes encuestados señalan que definitivamente sí y probablemente sí tienen la capacidad en el uso y manejo del software específico para el diseño de materiales en diversos formatos. Mientras el otro $50 \%$ se consideran indecisos y probablemente no tiene ésta competencia (Tabla 3). Algunos docentes optan por continuar con la forma de enseñanza antigua, por lo que aún no hacen uso de las nuevas herramientas tecnológicas en el proceso enseñanza-aprendizaje y otros lo hacen de manera incorrecta, esto demuestra un grave problema al quedar obsoletos en los cambios tecnológicos.

\section{Tabla 4}

Diseña ambientes de aprendizaje mediados por TIC para fomentar el desarrollo de las competencias de los estudiantes

\begin{tabular}{lllll}
\hline & Frecuencia & Porcentaje & $\begin{array}{l}\text { Porcentaje } \\
\text { válido }\end{array}$ & $\begin{array}{l}\text { Porcentaje } \\
\text { acumulado }\end{array}$ \\
\hline Definitivamente No & 3 & 5.4 & 5.4 & 5.4 \\
Probablemente No & 11 & 19.6 & 19.6 & 25.0 \\
Indeciso & 25 & 44.6 & 44.6 & 69.6 \\
Probablemente Sí & 13 & 23.2 & 23.2 & 92.9 \\
Definitivamente Sí & 4 & 7.1 & 7.1 & 100.0 \\
Total & 56 & 100.0 & 100.0 & \\
\hline
\end{tabular}


En la tabla 4, sólo el 30.3\% de los docentes indica que diseña ambientes de aprendizaje mediados por TIC para fomentar el desarrollo de las competencias de los estudiantes. Bautista et al. (2014) señalan que uno de los problemas que se han enfrentado las instituciones educativas no ha sido la integración de las TIC a los procesos de enseñanza-aprendizaje, porque una vez que se posee la tecnología, el tema que surge es cómo los profesores pueden hacer uso de ella, y de qué manera la van a integrar a sus métodos de enseñanza, ya que su formación TIC es deficiente.

\section{Tabla 5}

Utiliza variedad de textos e interfaces para transmitir información y expresar ideas propias combinando texto, audio, imágenes estáticas o dinámicas, vídeos y gestos

\begin{tabular}{lllll}
\hline & Frecuencia & Porcentaje & $\begin{array}{l}\text { Porcentaje } \\
\text { válido }\end{array}$ & $\begin{array}{l}\text { Porcentaje } \\
\text { acumulado }\end{array}$ \\
\hline Definitivamente No & 4 & 7.1 & 7.1 & 7.1 \\
Probablemente No & 11 & 1.6 & 19.6 & 26.8 \\
Indeciso & 16 & 28.6 & 28.6 & 55.4 \\
Probablemente Sí & 15 & 26.8 & 26.8 & 82.1 \\
Definitivamente Sí & 10 & 17.9 & 17.9 & 100.0 \\
Total & 56 & 100.0 & 100.0 & \\
\hline
\end{tabular}

El $44.7 \%$ de los encuestados, lejos del deseado $100 \%$, utiliza variedad de textos e interfaces para transmitir información y expresar ideas propias combinando texto, audio, imágenes estáticas o dinámicas, vídeos y gestos (Tabla 5). Es de importancia que el docente cree y busque continuamente nuevas ideas y estrategias en la enseñanza para que los alumnos saquen el máximo partido a sus posibilidades. En el ámbito de la educación virtual, es de gran ayuda el incorporar lenguajes multimedia (imagen, audio y video digitales), nuevos dispositivos para actividades en el aula virtual (quizzes, encuestas, boletines, calendarios, entre otros) y formas de comunicación uno a muchos y bidireccionales (chat, foros, entre otros), así como contenidos preparados que incluyen objetos de aprendizaje. Sin embargo, la virtualización de los materiales, deben aplicarse criterios de calidad que garanticen la accesibilidad, seguridad, economía cognitiva y la adquisición de conocimientos y competencias buscados, tal como lo muestran los estudios realizados en España por Moreno y Luchena (2014).

\section{Competencia docente en diseño instruccional}

De la competencia en diseño instruccional (Gráfica 2), se mencionan los indicadores que resultaron deficientes. Respecto a si conocen las diversas metodologías dirigidas a la construcción del conocimiento $33.9 \%$ y $19.6 \%$ de los investigados coincidieron en las alternativas probablemente sí y definitivamente sí. Sin embargo, la sumatoria de ambas cifras alcanzó 53.5\%, de nuevo alejado del ideal esperado de 100\%. La evaluación de los procesos de formación da impresiones sobre en qué medida los materiales didácticos han logrado facilitar la comprensión y mejora de los aprendizajes. Al respecto, de los docentes encuestados sólo $42 \%$ consideró que conocían y tenían la habilidad y el conocimiento sobre la evaluación de los procesos de formación, mien- 
tras el resto de los encuestados (57.1\%) se mostró indeciso y probablemente no tienen esa habilidad. Resulta claro que los materiales didácticos deben ser objeto prioritario de evaluación, ya que como señala Bautista et al. (sf), si bien todo tipo de enseñanza recurre a ellos, la educación a distancia en concreto depende fundamentalmente de los materiales, hasta tal punto que no puede entenderse sin ellos. En efecto, una parte considerable de cualquier tipo de comunicación educativa se realiza mediante materiales que ofrecen distintas posibilidades, que van desde la mera transmisión de contenidos hasta la oportunidad de reflexionar creativamente.

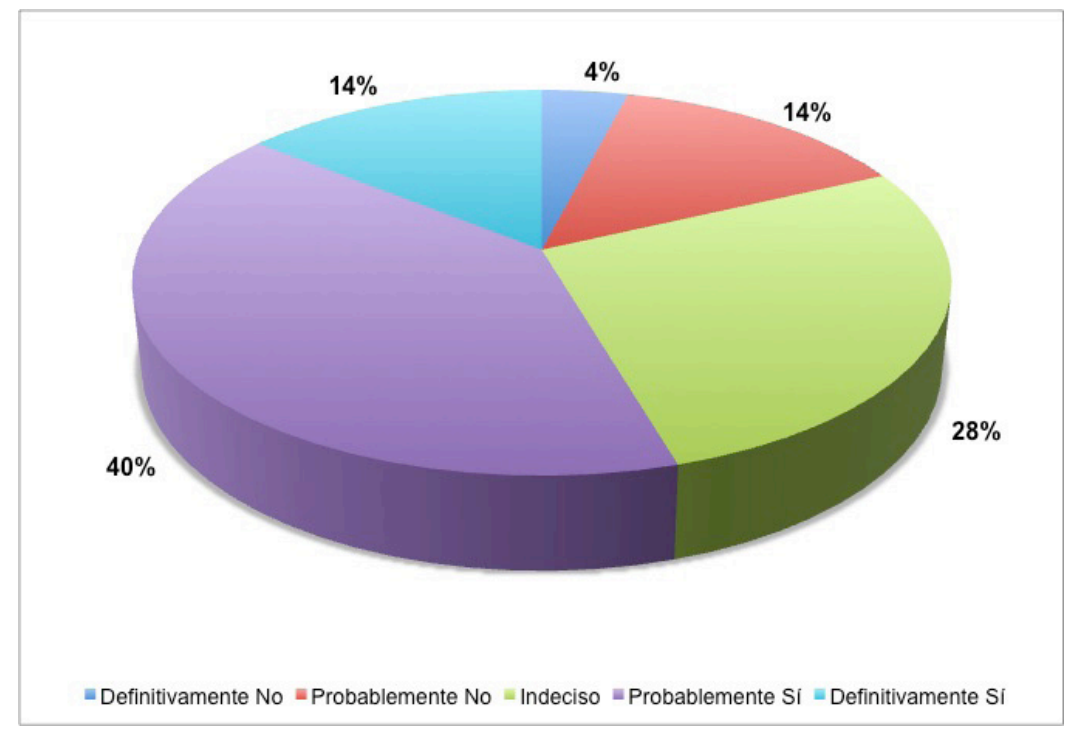

Figura 2. Competencia docente en diseño instruccional

Así mismo, 87.5\% de los docentes señaló que preparan el material didáctico para su materia, pero no lo circulan para revisión y aprobación. Mejorar la calidad de la educación, supone entre otras muchas actividades, perfeccionar los materiales que se utilizan en el proceso enseñanza-aprendizaje. Este perfeccionamiento puede realizarse desde la propia elaboración de los materiales y en la buena selección de materiales didácticos, así como en la adecuación de actividades de aprendizaje de los materiales que se encuentran ya en el mercado.

Se encontró que $55.3 \%$ de los docentes está indeciso, probablemente no y definitivamente no diseña instrucción que refleje un entendimiento de la diversidad de aprendices. La principal tarea que se tiene como docente es guiar a los alumnos a través de los recursos didácticos hacia el conocimiento, con el requisito de concretar el contenido educativo y adaptarlo a los intereses y habilidades de un alumno en particular.

\section{Soporte y apoyo de personal en el diseño, construcción, mantenimiento y distribución de materiales didácticos}

La gráfica 3 muestra que el 18\% de los docentes señalaron que cuentan con el soporte y apoyo de personal en el diseño, construcción, mantenimiento y distribución de materiales didácticos. Sin embargo, $82 \%$ de los docentes indicaron estar indecisos, que 
probablemente no y que definitivamente no contaban con el soporte y apoyo. Ante este contexto educativo que es el de educación virtual, obviamente, se presentan nuevas necesidades de formación, por lo que es preciso contar con un número suficiente de directivos, planificadores, autores, técnicos y docentes. Pero, además, es necesario que los docentes estén preparados y comprometidos con el importante papel de diseñar y elaborar materiales didácticos, con el adecuado asesoramiento pedagógico.

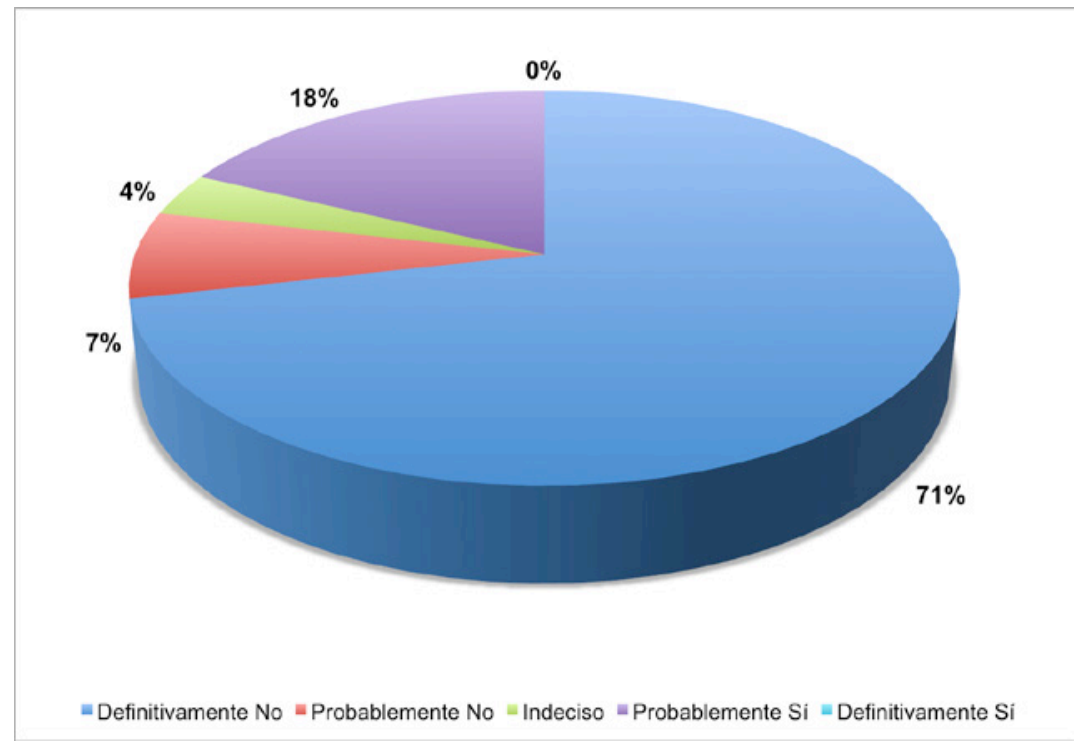

Figura 3. Soporte y apoyo de personal en el diseño, construcción, mantenimiento y distribución de materiales didácticos

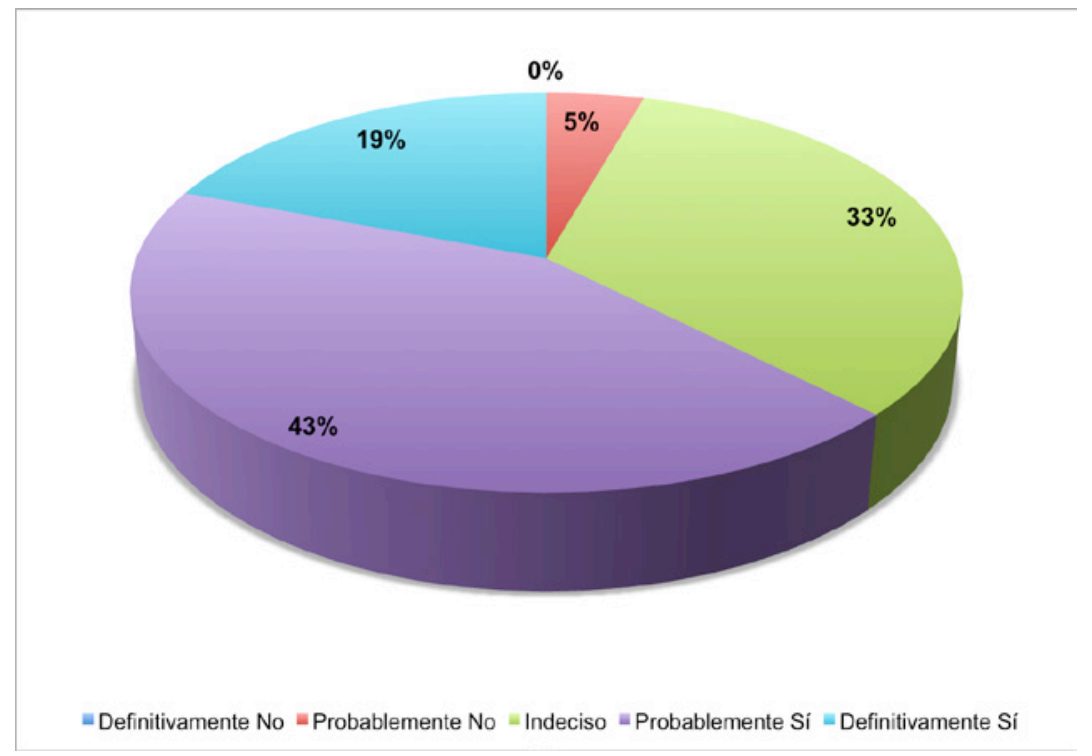

Figura 4. Características de los materiales didácticos elaborados por los docentes 
La figura 5 muestra que la mayoría de los docentes (62\%) consideran que los materiales didácticos cumplen con las características necesarias para ser un material de calidad. El 33\% de los docentes está indeciso y el resto 5\% señala que probablemente no cuentan con las características requeridas. El material didáctico ayuda a favorecer el desarrollo de las habilidades del alumno, así como perfeccionar las actitudes relacionadas con el conocimiento, a través del lenguaje oral y escrito, imaginación, socialización, entre otros. Promueve la estimulación de los sentidos y la imaginación dando paso al aprendizaje significativo. Es por eso, el diseñador del material didáctico debe tener capacidades, estilos cognitivos, intereses, conocimientos previos, experiencia y habilidades para el uso de los materiales didácticos.

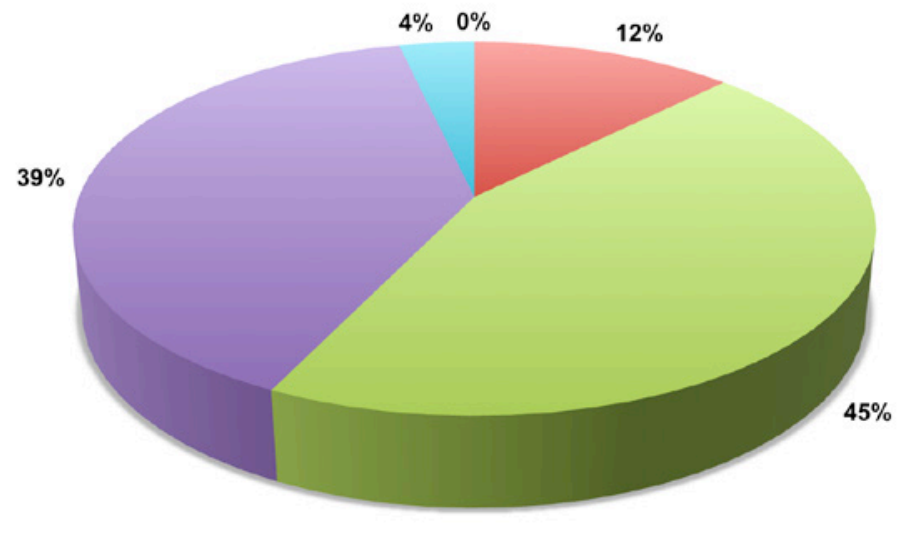

= Definitivamente No = Probablemente No $=$ Indeciso $=$ Probablemente Si $=$ Definitivamente Si

Figura 5. Satisfacción con el material didáctico y herramientas tecnológicas que dispone actualmente

De los docentes encuestados $43 \%$ se sienten satisfechos con el material didáctico y las herramientas tecnológicas con la que actualmente cuentan. Sin embargo, 57\% se manifestó indeciso y que probablemente no estaba satisfecho. La elaboración de los materiales y actividades didácticas exige como condición previa atender a los objetivos de aprendizaje que se desean conseguir y, de forma más concreta, a los conocimientos y competencias genéricas y específicas que el alumno deberá haber adquirido al finalizar su proceso formativo. En la virtualización de tales materiales, por su parte, deben aplicarse criterios de calidad que garanticen la accesibilidad, seguridad y la adquisición de conocimientos y competencias buscados. Es importante destacar que, en el ámbito de la educación virtual, el diseño de los materiales didácticos y actividades de aprendizaje en línea deben considerarse las particularidades de la modalidad y las necesidades de los alumnos implicados en el proceso formativo; de lo contrario, se corre el riesgo de que el aula virtual se convierta en un repositorio de información vacía de conocimiento (Santoveña, 2004). 


\section{Análisis de brechas entre importancia y nivel de desarrollo o dominio de cada competencia y sus indicadores}

Competencia docente en tecnologías de información y comunicaciones (TIC)

La competencia en TIC se compone de 8 atributos, los resultados señalan que la media general obtenida para importancia fue de: 4.4 y el nivel fue de 3.5. La figura 6, presenta de manera general los resultados obtenidos de la Competencia en TIC por importancia y nivel.

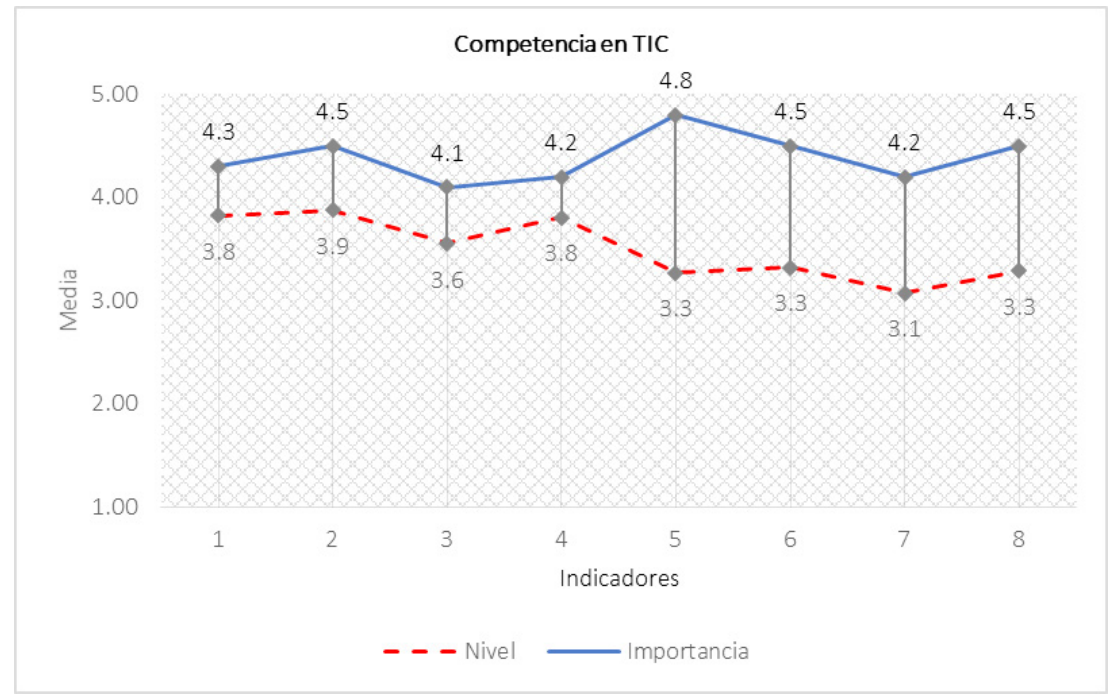

Figura 6. Resultados obtenidos de la dimensión Competencia en TIC, por importancia y nivel

Las diferencias presentadas en los atributos en cuanto importancia y nivel permiten identificar aquellos que se encuentran más distanciados, de este modo los atributos que presentan mayor brecha en sus puntajes son los ítem: "conoce una variedad de estrategias y metodologías apoyadas por las TIC, para planear y hacer seguimiento a su labor docente", "implementa estrategias didácticas mediadas por TIC, para fortalecer en los estudiantes aprendizajes que les permitan resolver problemas de la vida real", "diseña ambientes de aprendizaje mediados por TIC para fomentar el desarrollo de las competencias de los estudiantes" y "utiliza variedad de textos e interfaces para transmitir información y expresar ideas propias combinando texto, audio, imágenes estáticas o dinámicas, videos y gestos", se demuestra que los docentes aunque manejen las herramientas tecnológicas para elaborar materiales didácticos (53\%), se le dificulta desarrollar estrategias y metodologías para incorporar adecuadamente la tecnología en su enseñanza. 
Competencia docente en diseño instruccional

La competencia en diseño instruccional se compone de 20 atributos, los resultados señalan que la media general obtenida para importancia fue de: 3.9 y el nivel fue de 3.5.

La figura 7, presenta de manera general los resultados obtenidos de la Competencia en diseño instruccional por importancia y nivel.

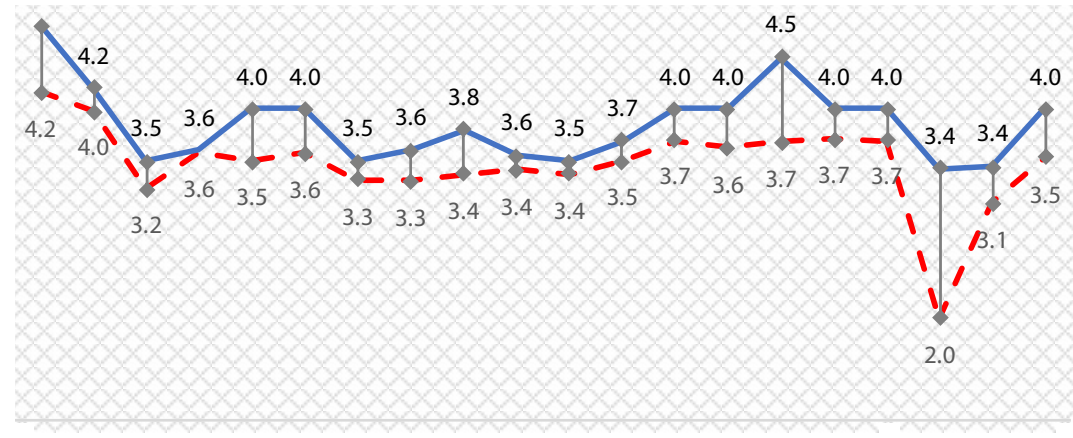

Figura 7. Resultados obtenidos de la dimensión Competencia en diseño instruccional, por importancia y nivel

Los dos atributos que presentan mayor brecha en sus puntajes son: "analiza el contexto educativo y selecciona estrategias adecuadas para los materiales didácticos" y "prepara un documento de diseño y lo circula para revisión y aprobación". Esto indica, que no todos los docentes vinculan los aprendizajes de sus alumnos con situaciones y problemáticas de su entorno. Además, la mayoría de los docentes no presentan su material didáctico para que sea sometido a una revisión y aprobación por parte de la academia. Esto es de gran importancia ya que se evalúa la pertinencia del mismo.

\section{Discusión y conclusiones}

Los docentes utilizan las tecnologías de información y comunicación (TIC) de una manera general, pero es obvio que requieren de nuevos modelos de aprendizaje, de nuevos procedimientos y estrategias didácticas que integren las TIC en todo el proceso educativo. Las TIC ofrecen nuevas posibilidades en el diseño y proceso de propuestas de enseñanza-aprendizaje, pero los docentes no adoptan o desconocen de nuevas metodologías de enseñanza que busquen potenciar el desarrollo cognitivo de los estudiantes. Bautista et al. (2014) señalaron que uno de los mayores problemas a que se han enfrentado las instituciones educativas, ha sido la integración de las TIC a los procesos de enseñanza-aprendizaje. Además, estos mismos autores, especificaron que una vez que se posee la tecnología por parte de la institución, el tema que surge es cómo los profesores pueden hacer uso de ella, y de qué manera la van a integrar a sus métodos de enseñanza, ya que su formación TIC es considerada como deficiente.

Los docentes consideran que carecen de las competencias demandadas para la elaboración de materiales didácticos para la modalidad virtual. Los docentes actuales requieren de una competencia apropiada para el diseño de materiales con una delineación didáctica acorde a las características de los estudiantes, que responda al logro de los objetivos formativos establecidos. Los investigadores Tynybekovna et al. 
(2013) en un estudio realizado en Turquía, concluyeron que el nivel de entrenamiento entre los docentes debe ser considerado como fundamental y prioritario. Estos mismos investigadores sugirieron perfeccionar la competencia de diseño instruccional entre todos los docentes. Es de gran importancia que los docentes estén preparados con las competencias adecuadas para establecer entornos de aprendizaje $y$, de esta manera, satisfacer las necesidades de los estudiantes (Savchenko, 2013). Por lo tanto, es imprescindible para los docentes actuales ampliar sus habilidades para satisfacer estos desafíos.

La mayoría de los encuestados en este estudio no están satisfechos con los materiales didácticos y herramientas tecnológicas con los que disponen en la actualidad. La principal necesidad identificada en la elaboración de materiales didácticos se vinculó con la carencia de apoyo y soporte; es decir, de una estructura que les ayude en la elaboración de los mismos, pero además esto implicará un mayor esfuerzo y tiempo para el docente. Tal como lo muestran los estudios realizados en España por Moreno y Luchena (2014), en la virtualización de los materiales, deben aplicarse criterios de calidad que garanticen la accesibilidad, seguridad, economía cognitiva y la adquisición de conocimientos y competencias buscados. Tal es el caso de Prats y Ojando (2015) que demostraron, por medio de una investigación donde trabajaron con dos grupos de control (que utilizaron los mismos contenidos sin utilizar TIC) y experimental (se utilizaron metodologías y materiales novedosos utilizando TIC), que los alumnos que han utilizado de manera sistemática (según la metodología y planificación previamente establecida con la adecuada formación del profesorado) los contenidos didácticos digitales han obtenido una mejora significativa de sus aprendizajes y rendimiento académico y los grupos control han obtenido solamente una pequeña mejora sin significatividad estadística.

En relación al resultado de la competencia tecnológica, este es congruente con lo encontrado por Fernández-Cruz y Fernández-Díaz (2016) en colegios de la Comunidad de Madrid, España, en el sentido de que existe una laguna importante en la formación del profesorado en el uso de las TIC y su aplicación en las aulas. Estos investigadores detectaron que si los docentes no poseen conocimientos técnicos del uso y aplicación de las herramientas digitales, difícilmente se podrán implementar en el mundo educativo. En otras palabras, la carencia que tiene el profesorado en el manejo de las herramientas tecnológicas les impide aplicarlas con efectividad en las actividades educativas con sus alumnos. Por otro lado, en un estudio realizado en Colombia por Angarita-Velandia et al. (2008) sobre el uso de material didáctico innovador, estos autores señalaron que dichos materiales motivan al estudiante en la apropiación de conocimientos, brindando al mismo tiempo una experiencia significativa, que posibilitará en forma posterior, inclinarse hacia el estudio y profundización de las temáticas.

\section{Referencias bibliográficas}

Angarita-Velandia, M. A., Fernández-Morales, F. H., \& Duarte, J. E. (2008). Relación del material didáctico con la enseñanza de ciencia y tecnología. Educación y Educadores, diciembre, 49-60.

Antonenko, P., Toy, S., \& Niederhauser D. (2004). Modular object-oriented Dynamic Learning Enviroment: what open source has to offer. Recuperado de: https:// files.eric.ed.gov/fulltext/ED485088.pdf 
Aznar-Díaz, I., Raso-Sánchez, F., Hinojo-Lucena, M., \& Romero-Díaz, J. (2016). Percepciones de los futuros docentes respecto al potencial de la ludificación y la inclusión de los videojuegos en los procesos de enseñanza-aprendizaje. Educar, 53(1), 11-28. doi: https://doi.org/10.5565/rev/educar.840

Bautista, L. R., Martínez, R. R., \& Sainz, I. M. La evaluación de materiales didácticos para la educación a distancia. UNED, España. Recuperado de: http://www.biblioteca.org.ar/libros/142108.pdf

Bautista, S. M. G., Martínez, M. A. R., \& Hiracheta, T. R. (2014). El uso de material didáctico y las tecnologías de información y comunicación (TIC's) para mejorar el alcance académico. Ciencia y Tecnología. Recuperado de: http://www.palermo. edu/ingenieria/pdf2014/14/CyT_14_11.pdf

Campo S. M. F., Segovia de Cabrales, R., Martínez, B. P. P., \& Rendón, O. H. J. (2013). Competencias TIC para el Desarrollo Profesional Docente. Colección Sistema Nacional de Innovación. Educativa con uso de Nuevas Tecnologías. ISBN: 978-958750-762-1. Recuperado de: http://www.colombiaaprende.edu.co/html/micrositios/1752/articles318264_recurso_tic.pdf

Carmona, S. E., \& Rodríguez, S. E. (2017). Buenas prácticas en la educación superior virtual a partir de especificaciones de estándares e-Learning. Sophia, 13(1), 13-26.

Coll, C., \& Monereo, C. (2008). Psicología de la educación virtual. Aprender y enseñar con las Tecnologías de la Información y la Comunicación. Madrid: Morata.

Corrales, P. M. I., \& Sierras, G. M. (2012). Diseño de medios y recursos didácticos. España: Innovación y Cualificación.

Facundo, A. (2010). La educación superior a distancia en Colombia luego de tres décadas de desarrollo. En Rama, C. y Pardo, J. (Eds.), La educación superior a distancia: miradas diversas desde Iberoamérica. Recuperado de: http://www.uned. es/catedraunescoead/cosypedal/La\%20EaD\%20Iberoamerica,\%20miradas\%20 diversas\%20-\%20Ram.pdf

Fernández-Cruz, F., \& Fernández-Díaz, M. (2016). Los docentes de la Generación Z y sus competencias digitales. Comunicar, 24(46), 97-105. doi: https:doi.org/10.3916/ C46-2016-10

Lokar, M. (2011). Development of E-Content for Teaching Mathematics. Electronic Journal Of Mathematics \& Technology, 5(2), 149-158.

Lloréns, L., Espinosa, Y., \& Castro M. L. (2013). Criterios de un modelo de diseño instruccional y competencia docente para la educación superior escolarizada a distancia apoyada en TICC. Sinéctica, 41. Recuperado de: http://sinectica.iteso. $\mathrm{mx} /$ assets/files/articulos/41_criterios_de_un_modelo_de_diseno_instruccional_y_competencia_docente_para_la_educacion_superior_escolarizada_a_distancia_apoyada_en_ticc.pdf

Mishra, P., \& Koehler, M. J. (2006). Technological pedagogical content knowledge: a new framework for teacher knowledge. Teachers College Record, 6, 1017-1054.

Moreno G. S., \& Luchena M.G. M. (2014). Formación e-learning en la enseñanza superior del Derecho: experiencia en la Universidad de Castilla-La Mancha. Revista De Docencia Universitaria, 12(3), 293-318.

Pellón, R. T., Miranda, D. R., González, S. B., \& Reyna, C. H. C. (2017). Las tecnologías de la información y la comunicación en la enseñanza de inglés en Ciencias Médicas. Revista Cubana de Educación Médica Superior, 31(2), 1-8. Recuperado de: http:// 
search.ebscohost.com/login.aspx?direct=true\&db=a9h\&AN=128130130\&lan$\mathrm{g}=\mathrm{es} \&$ site=ehost-live

Prats I., F. M. A., \& Ojando P. E. S. (2015). ¿Pueden las TIC mejorar los resultados académicos? Diseños formativos y didácticos con soporte TIC que mejoran los aprendizajes: el caso de los contenidos digitales de ortografía de Digital-Text. Educatio Siglo XXI, 33(3), 85-101. doi: http://dx.doi.org/10.6018/j/240841

Rodríguez, A. G., Gómez, L. V., \& Ariza D. M. (2014). Calidad de la Educación Superior a Distancia y Virtual: Un Análisis de Desempeño Académico en Colombia. Investigación y Desarrollo, 22(1), 79-119.

Santoveña, C. S. M. (2004). Metodología didáctica en entornos virtuales de aprendizaje, Revista Etic@net, 3. Universidad de Granada. Recuperado de: http://goo.gl/ Vo2nTm

Savchenko, O. (2013). Didactic adaptation of University graduates: Efficiency enhancing conditions. American Journal of Education Research 1(11), 538-542.

Torres, O. J. A., \& Gutiérrez, G. M. C. (2017). Formación Pedagógica Hibrida en Docentes Licenciados a través De La Educación a Distancia Y Virtual. Revista de Pedagogía, 38(103), 275-292. Recuperado de: http://search.ebscohost.com/login. aspx?direct=true\&db=zbh\&AN=136604912\&lang=es\&site=ehost-live

Tynybekovna, N. S., Meibekovich, B. K., Talgatovna, K. B., \& Pernebaevna, M. G. (2013). To the problem of using the information and computer technology for specialist's competitive training in high school. Procedia-Social and Behavioral Sciences: 89 213-217. Recuperado de: https://www.sciencedirect.com/science/article/pii/ S1877042813029674 